\title{
Maternal Risk Factors Predicting Child Physical Characteristics and Dysmorphology in Fetal Alcohol Syndrome and Partial Fetal Alcohol Syndrome
}

\author{
Philip A. Maya, ${ }^{\text {, }}$, Barbara G. Tabachnick ${ }^{b}$, J. Phillip Gossage ${ }^{a}$, Wendy O. Kalberg ${ }^{a}$, Anna- \\ Susan Marais ${ }^{c}$, Luther K. Robinson ${ }^{d}$, Melanie Manning ${ }^{e}$, David Buckley ${ }^{\mathrm{a}}$, and H. Eugene \\ Hoyme $^{f}$ \\ aThe University of New Mexico, Center on Alcoholism, Substance Abuse, and Addictions \\ (CASAA). 2650 Yale SE, Albuquerque, NM, 87106 \\ ${ }^{\mathrm{b}}$ California State University, Northridge \\ cUniversity of Stellenbosch, Faculty of Health Sciences, P.O. Box 10963, Tygerberg, Republic of \\ South Africa 7505 \\ dState University of New York, Buffalo, School of Medicine, Department of Pediatrics, 219 Bryant \\ Street Buffalo NY, 14222 \\ eStanford University, School of Medicine, Department of Pediatrics 300 Pasteur Drive, H315 \\ Stanford, CA 94305 \\ fThe University of South Dakota, Sanford School of Medicine, Department of Pediatrics, 1305 W. \\ $18^{\text {th }}$ Street, PO Box 5039, Sioux Falls, SD 57117-5039
}

\begin{abstract}
Background-Previous research in South Africa revealed very high rates of fetal alcohol syndrome (FAS), of 46 to 89 per 1,000 among young children. Maternal and child data from studies in this community summarize the multiple predictors of FAS and partial fetal alcohol syndrome (PFAS).
\end{abstract}

\begin{abstract}
(c) 2011 Elsevier Ireland Ltd. All rights reserved.
Corresponding author: Philip A. May, Professor of Sociology and Family and Community Medicine, The University of New Mexico, CASAA, 2650 Yale SE, Albuquerque, NM 87106. pmay@unm.edu, Phone: (505) 925-2307, Fax: (505) 925-2313.

Publisher's Disclaimer: This is a PDF file of an unedited manuscript that has been accepted for publication. As a service to our customers we are providing this early version of the manuscript. The manuscript will undergo copyediting, typesetting, and review of the resulting proof before it is published in its final citable form. Please note that during the production process errors may be discovered which could affect the content, and all legal disclaimers that apply to the journal pertain.

Contributors

Philip A. May served as the Principal Investigator for all phases of this research and drafted the majority of the material of the first draft of this paper. Barbara Tabachnick constructed and performed all of the multiple correlation statistical analysis and models for the paper. She also wrote the first drafts of the major data analysis section and part of the results section. J. Phillip Gossage served as the data manager for all phases of this project, constructed the basic data sets, and produced all of the descriptive statistical analyses. Wendy O. Kalberg, oversaw and along with David Buckley, contributed all of the cognitive-behavioral testing of the children in south Africa and the summary analysis of each case appearing in the case conference. Anna-Susan Marais was the program manager for all field operations in South Africa for the last (third) phase of the project studies, and she oversaw all clinical and testing operations in the field. Luther Robinson, Melanie Manning, and Eugene Hoyme each were the dymorphologists for the studies in the field in South Africa, and who contributed to the first drafts of the description of the clinical components of the project. All authors participated in the design of the design, theory, and substantive content of this paper and suggested data analysis questions that were addressed. Also, all authors have read and contributed the final draft of the manuscript for submission.
\end{abstract}

Conflict of Interest

None of the authors have any conflicts of interest to declare. 
Method-Sequential regression was employed to examine influences on child physical characteristics and dysmorphology from four categories of maternal traits: physical, demographic, childbearing, and drinking. Then, a structural equation model (SEM) was constructed to predict influences on child physical characteristics.

Results-Individual sequential regressions revealed that maternal drinking measures were the most powerful predictors of a child's physical anomalies $\left(R^{2}=.30, \mathrm{p}<.001\right)$, followed by maternal demographics $\left(R^{2}=.24, \mathrm{p}<.001\right)$, maternal physical characteristics $\left(R^{2}=.15, \mathrm{p}<.001\right)$, and childbearing variables $\left(R^{2}=.06, \mathrm{p}<.001\right)$. The SEM utilized both individual variables and the four composite categories of maternal traits to predict a set of child physical characteristics, including a total dysmorphology score. As predicted, drinking behavior is a relatively strong predictor of child physical characteristics $(\beta=0.61, \mathrm{p}<.001)$, even when all other maternal risk variables are included; higher levels of drinking predict child physical anomalies.

Conclusions-Overall, the SEM model explains $62 \%$ of the variance in child physical anomalies. As expected, drinking variables explain the most variance. But this highly controlled estimation of multiple effects also reveals a significant contribution played by maternal demographics and, to a lesser degree, maternal physical and childbearing variables.

\section{Keywords}

fetal alcohol spectrum disorders (FASD); fetal alcohol syndrome (FAS); partial fetal alcohol syndrome (PFAS); dysmorphology; maternal risk factors; human malformations

\subsection{INTRODUCTION}

The quest to understand the maternal influences on child physical traits and dysmorphology has a long history in the study of fetal alcohol syndrome (FAS) and other fetal alcohol spectrum disorders (FASD) (Pierog et al., 1979; Abel, 1986; Abel and Hannigan, 1995; Hankin, 2002; Alvik et al., 2006a; May et al., 2008). Through descriptive data and comparative analyses with case control studies in a variety of populations, multiple maternal risk factors have been identified. However, collecting extensive and complete data on material risk for FAS and partial fetal alcohol syndrome (PFAS), the most severely dysmorphic forms of FASD, has proven to be difficult in most populations. For this and other reasons, our knowledge and understanding of the relative contribution of the individual maternal risk factors for FASD is currently limited.

In this paper we utilize the largest, most complete, matched data sets on child physical characteristics and maternal risk factors for these children and their mothers from a community in South Africa. The objective of this paper is to produce a single, summative, statistical model of the relative importance of many of the previously identified maternal risk variables for FASD.

\subsection{Maternal Risk Factors for FASD}

The quantity, frequency, and timing of alcohol consumption are the key variables in producing FASD, and the pattern of drinking that is most harmful to the fetus is heavy episodic (binge) drinking (West and Goodlett, 1990; Thomas et al., 1996, Maier and West, 2001; Viljoen et al., 2002; May et al., 2005; 2008). So it is important that studies of human maternal risk factors for FASD include multiple measures of drinking styles that capture the pattern of consumption: how much is consumed, how often, and at what time during the pregnancy? But obtaining accurate measures from maternal reports is fraught with challenges (Jacobson et al., 1991; Alvik et al., 2006a, 2006b, 2006c; Hankin, 2002; Malet et al., 2006; Bad Heart Bull et al., 1999; Floyd et al., 1999; Kristjanson et al., 2007; Whaley 
and O'Connor, 2003; Primatesta et al., 1993; Robles and Day, 1990; Serdula et al., 1991; Waterson and Murray-Lyon, 1989; Hannigan et al, 2010). In essence, the more often a woman drinks during pregnancy, the greater amounts that she drinks (especially over short periods of time), and if drinking continues throughout the gestation of the child, the more likely a child is to have an FASD, especially the more severely dysmorphic forms of FAS and partial fetal alcohol syndrome (PFAS) (Pierce and West, 1986; Abel, 1998; Stratton et al., 1996; Earnhart et al., 1987; Flynn, 2008).

But maternal risk is not as simple as alcohol consumption alone. Maternal risk has been found to vary widely from woman to woman based on childbearing variables: maternal age, gravidity, and parity (May et al., 1983; Jacobson et al, 1996, 1998; May et al., 2005, 2006, 2008). Older women who drink in a "binge" or heavy episodic manner, who have been pregnant more, and have had more children, have a higher probability of bearing a child with an FASD. FASD occurrence has also been found to vary by demographic variables such as socioeconomic status (SES) (Baily, 1990; Darrow et al., 1992; Crome and Glass, 2000; Abel, 1995; May et al., 2005, 2008). Although births of FASD children have been documented in all strata, FASD children are most likely to be born to women of the lower social status (Bignol, et al., 1987) as measured by factors such as maternal education, occupation, and residence (Abel, 1995; Abel and Hannigan, 1995; Viljoen, et al., 2002; May et al, 2005; 2008). Finally, recent population-based studies have pointed to maternal physical variables as important risk factors for FASD: mother's height, weight, and a summary measure, body mass index (BMI), are influential. Lighter, shorter women, with a low BMI are over represented in groups of mothers who have a child with an FASD as compared with other, larger mothers who report relatively similar amounts of drinking. Larger women appear to be less likely to give birth to a child with an FASD (Khaole et al., 2004; May et al, 2004); 2005, 2008). This may be both a physiological effect and evidence of poor nutrition as enhancing risk for an FASD (Khaole et al., 2004; Sokol, et al., 1986; Abel and Hannigan, et al, 2005; Abel, 1998; Badger et al., 2005; Shankar et al., 2006, 2007; Thomas et al., 2004).

\subsection{Multiple Correlation Studies}

Maternal risk factor studies have seldom benefited from access to large samples of children with fetal alcohol syndrome (FAS) or other severely dysmorphic forms of fetal alcohol spectrum disorders (FASD) or from rich and complete population-based maternal risk data matched to the child data. Therefore, few multiple correlation studies have been carried out on samples of high risk mothers who have produced a child with FAS or PFAS.

One such multiple correlation study, however, was reported from the Cleveland Fetal Alcohol Study by Sokol, et al., (1986). In their analyses a sample of 25 children with FAS and maternal risk factor data from their mothers were combined with 50 matched, normal controls and data from their mothers. Significant differences were found with t-test analyses between the two maternal groups. The mothers of FAS children were characterized by higher maternal age, increased frequency of black race, higher gravidity, and higher parity. For alcohol variables, the mothers of children with FAS had higher Michigan Alcohol Screening Test (MAST) scores, more drinking days, greater amounts of alcohol consumed on drinking days, a different drinking pattern (binge or heavy, episodic drinking predominated), and a higher proportion of their alcohol consumed was beer. Their data set was further analyzed by stepwise, discriminate function analysis to differentiate between the two groups. Race and higher MAST scores were the two key variables that were significant discriminators between the two groups; but further analyses indicated that both the race variable and the MAST scores were absorbing a great deal of variance because of specific variations in traits among these subjects who fell into these general categories. For example, significant contributors embedded within the Black race variable were reported as maternal 
age, narcotic use, proportion of drinking days, and other drinking variables. Significant factors embedded within the MAST variable were the pattern of drinking (binge), gestational age of the child at screening, and other drinking variables as in the above t-test analysis. Therefore, when drinking days and MAST scores were added to parity and race for further discriminant analysis, these four variables were found to account for a majority of what the authors stated was the estimated explainable variance (estimated by the ratio $R^{2} / R^{2}$ max which is not comparable to other, standard $\mathrm{R}^{2}$ measures of variance). Logistic regression analysis indicated that in the presence of all of the above four significant maternal risk factors, the chance is $85 \%$ that a child would have FAS; and in the absence of all four of these maternal risk variables, a child would have less than a $2 \%$ chance of having FAS (Sokol, et al., 1986). Therefore, the pioneering study by Sokol and colleagues provides evidence that unraveling the various maternal influences on FASD is complex and not easily summarized with statistically-controlled methods and small and limited data sets. The data sets that we employ in this paper are indeed much larger and allow for more sophisticated methods of statistical control.

\section{METHODS}

\subsection{Diagnostic Criteria}

Diagnostic components of the revised U.S. Institute of Medicine (IOM) categories (Hoyme, et al., 2005) were used to assess FAS and PFAS in the children. For the diagnosis of FAS a child must have: 1.) evidence of a characteristic pattern of minor facial anomalies including at least 2 or more of the key facial features of FAS (palpebral fissures $\leq 10$ th centile, thin vermilion border, or smooth philtrum), 2.) evidence of prenatal and/or postnatal growth retardation (height (hgt.) or weight (wgt.) $\leq 10$ th centile), 3.) evidence of deficient brain growth (structural brain anomalies or occiptofrontal head circumference (OFC) $\leq 10$ th centile), and if possible, 4.) confirmation of maternal alcohol consumption directly from the mother or a knowledgeable collateral source. For a diagnosis of Partial FAS (PFAS), a child must have: 1.) evidence of a characteristic pattern of facial anomalies including 2 or more of the three mentioned above, 2.) one or more other characteristics, such as prenatal or postnatal growth retardation ( $\leq 10$ th centile) in height or weight), 3.) small OFC $(\leq 10$ th centile), and/or evidence of a complex pattern of behavioral or cognitive abnormalities inconsistent with developmental level and unexplainable by genetic composition, family background, or environment alone, and if possible, 4.) confirmation of maternal alcohol consumption directly from the mother or a collateral source. There was no attempt in this study to diagnose any of the other, less dysmorphic (usually less severe) forms of the IOMdefined fetal alcohol spectrum, alcohol-related birth defects (ARBD) or alcohol-related neurodevelopmental disorder (ARND), as the study sampling methods were keyed by growth and structural deficits not obviously present in children with ARND or ARBD. Every child with a FASD diagnosis in this paper met each of the IOM criteria for FAS or PFAS, and criteria for alcohol exposure during pregnancy were met in $96.2 \%$ of all FASD cases from direct maternal interview and $100 \%$ from collateral sources.

\subsection{Screening for FASD Cases and Normal Controls}

This study is a multiple correlation, analytical analysis utilizing the measured and reported characteristics of children with FAS and PFAS and randomly-selected normal (non-FASD) control/comparison subjects attending the same schools in a single town and its surrounding rural areas in the Western Cape province of South Africa. Also, the mothers of the FASD subjects and the normal children were interviewed extensively regarding maternal risk factors of FASD. It is an effort to understand the relative contribution of specific and complex maternal trait associations with child physical traits, dysmorphology of children with FASD, specifically in the most dysmorphic cases (FAS and PFAS). 
Three waves of research were initiated in 1997, 1999, and 2002. All protocols and procedures were approved by the University of New Mexico Human Research Review Committee, the Research Ethics Committee of the University of Cape Town, and a single site assurance committee at the local municipality.

All $1^{\text {st }}$ grade children attending public schools, with active consent to participate $(\mathrm{n}=2667$ which is $91 \%$ of all enrolled students at the time), were screened for height, weight, and head circumference. In each wave, children $\leq 10^{\text {th }}$ centile on height and weight and/or head circumference were advanced further in the diagnostic process, and teams of dysmorphologists (blinded from the child's history and one another's findings) examined the children for growth, development, and anomalous features. The majority of the population in this study area is classified as "Coloured," a term used for generations to describe people of mixed Black African, European, and Asian ancestry. Because of the small size of the South African Coloured population of this region, this method of screening using National Center for Health Statistics (NCHS) charts (which are also used as a standard by the South African health officials) produced a full screening of $35 \%$ of the entire first grade populations as possible cases of FASD.

In addition, a number of children were chosen via random number tables from all of the first grade children with consent to participate. These randomly-selected children were selected as controls/comparison children and advanced throughout the entire study along with the suspected cases. They received all of the same screens, diagnostic services and cognitivebehavioral testing as did the suspects for an FASD diagnosis (see also section 2.2).

Measurements and observations of physical characteristics and traits were recorded for all child participants on a quantified dysmorphology checklist, where a high score indicates more features consistent with a diagnosis within the continuum of FASD (Hoyme, et al., 2005; Viljoen, et al., 2007; May, et al., 2007). Following the dysmorphology exam, children suspected of having an FASD, and the randomly-selected controls, were administered cognitive, behavioral, and life skills tests (Adnams, et al., 2001) to assess their cognitive and behavioral development. Next, biological mothers of the children (both suspected cases and controls) were located and interviewed about maternal risks. Finally, a formal case conference was held for each child in the study where clinicians from each of the substantive domains (child physical findings, cognitive behavioral testing, and maternal risk factor interviews) reviewed findings on all tests/exams of both cases and controls, and final diagnoses were made using revised IOM criteria (Hoyme, et al., 2005; Stratton, et al., 1996). Of the 185 children with FAS or PFAS, $72.4 \%$ were diagnosed with FAS, and $28.6 \%$ received a diagnosis of PFAS. One child with FAS or PFAS was white, the remainder were Coloured or Black.

\subsection{Controls/Comparison Subjects - Children and Mothers}

All first grade children with consent to participate were eligible for selection as non-FASD, normal controls/comparison cases; 376 children were selected by random methods and were confirmed not to have an FASD. The analysis in this paper utilizes twice as many control/ comparison subjects as cases of FASD. Because of the random selection methods, controls are representative of the local population.

\subsection{Interviews with Mothers of FASD Children and Controls}

The total number of mothers of children with FAS and PFAS who theoretically could have been included in this study is 185 . Interviews were performed in the field (generally the women's houses, but occasionally in a private room in a school or church) by a cadre of well trained and experienced researchers: two research nurses, one public health worker, two 
community social workers, and one public health researcher with formal training as an educator. All interviews were in Afrikaans, the local, first language of the majority. The interview content changed slightly over the years, mostly through addition of more variables. For example, measuring the mother's height and weight was added after the first wave. Given that the vast majority of the local population was South African Coloured, 92\% of the mothers interviewed were Coloured, $4 \%$ were South African Black, and $4 \%$ White.

Because of death, migration, and other situations, complete maternal interviews were performed with 159 (79.8\%) mothers of FAS and PFAS children. When the mothers were dead or could not be located, as much information as possible on the maternal risk variables was collected from knowledgeable collateral sources such as family members. All of the mothers of children with an FASD diagnosis who were alive and contacted by members of the research team agreed to be interviewed.

The mothers of the randomly-selected control children became the normal maternal comparison subjects. Data were collected for mothers of FAS and PFAS children and control mothers at the same time that the data were collected for any of the suspected cases. And, as the diagnosis had not yet been made for any of the children at any point in the data collection, neither mothers nor interviewers knew the diagnosis of a child during the maternal interviews. Collateral sources were utilized on the small proportion of the control mothers not interviewed. Because of the screening procedures, confirmation was established that none of the children in the control group had an FASD, and that none of the control mothers had given birth to a child with an FASD in this particular (index) pregnancy.

Studies in this region among the Coloured population have indicated that mothers are quite forthcoming and forthright with sensitive information (Viljoen, et al., 2002; May et al., 2005 ; 2008). Over the course of the three waves of research, only six mothers of children diagnosed with FAS and PFAS (3.8\%) have denied using alcohol during an index pregnancy; yet in all of these six cases, diagnostic exams and cognitive-behavioral tests performed on each of these children by multiple dysmorphologists and testing by psychologists, confirmed that a diagnosis of FAS or PFAS was appropriate per IOM guidelines (Hoyme, et al., 2005; Stratton, et al., 1996). Information from the mothers interviewed (cases and controls), and some collateral information for key variables from those not interviewed, provided the maternal data $(\mathrm{n}=561)$ for this analysis.

\subsection{Questionnaire}

All mothers were administered identical questionnaires, and all participants received gift baskets of food staples as incentives. The questionnaire was developed and piloted specifically for this population, and a detailed description of its development and content is found in previous publications. (May et al., 2005; 2008; Viljoen, et al., 2002). The retrospective collection of information is designed to accurately reconstruct behavior and traits before, during, and after gestation of the index child.

Briefly, the questionnaire consists of both fixed responses and open ended items. It was piloted and validated in our earliest studies in South Africa (Viljoen, et al. 2002; May et al., 2005). To establish rapport, nonthreatening questions were asked first, and alcohol consumption questions were asked in the context of dietary questions, a format and sequencing where responses regarding alcohol use have been found to be more accurate (King, 1994). Respondents were first asked about the health and drinking practices of their relatives and friends. Then the interview moved to information on health, diet ( 24 hour recall), and childbearing of the mother. The context, quantity, and frequency of the mother's current drinking were then explored via a 1-week, day-by-day log. Drinks were measured in standard ethanol units that equal 0.5 ounces of absolute alcohol, the equivalent of the 
American standard: $340 \mathrm{ml} \mathrm{can/bottle} \mathrm{of} \mathrm{beer} \mathrm{(5 \%} \mathrm{ethanol),} 120 \mathrm{ml}$ of wine (11\% ethanol), $95 \mathrm{ml}$ of wine (13.5\% ethanol), or $44 \mathrm{ml}$ of distilled spirits (43\% ethanol). Respondents viewed pictures of standard containers of local brands to calibrate exact amounts consumed (Kaskutas and Graves, 2001; Kaskutas and Kerr, 2008). Questions on current drinking were used as benchmarks to establish the method of reporting and for refreshing recall before timeline follow-back questions (Sobell, et al., 1988). Then gestational drinking was queried. A growing number of studies have indicated that retrospective post-natal assessment of gestational alcohol use is likely to be more accurate, or at least to provide higher levels of drinking than that collected in prenatal settings (Alvik, 2006a; Czarnecki, et al., 1990; Hannigan, et al., 2010). A copy of the questionnaire can be obtained from the corresponding author.

Body mass index (BMI) was calculated via the metric formula (Molarius, et al., 2000): weight in kilograms $\div$ (height in meters) ${ }^{2}$. The population in this study is representative of the small town and rural population of the Western Cape Province of South Africa were the majority Coloured (mixed race people of Black African, Asian, and White admixture) and the remainder were African Blacks and Whites.

\subsection{Data Analysis}

Data were entered via Epi Info (Dean et al., 1994) and transformed to SPSS (SPSS Inc., 2005) SAS (SAS Institute, 2005) and EQS (Bentler and Wu, 2005) for analysis. Also other statistical applications were utilized for specific data analysis purposes as described in detail in the appropriate place in the results section.

\subsection{Demographic Summary and the Structured Equation Model}

Table 1 summarizes the key demographic variables. Preliminary sequential regression analyses using SPSS REGRESSION first examined the prediction of dysmorphology from four sets of maternal characteristics: physical, demographic, childbearing, and drinking. A structural equation model (SEM) was then designed, using the extant literature on maternal risks for FASD as a guide for testing the contributions of specific and grouped maternal variables to the diagnostic traits of the children FAS and PFAS. Figure 1 illustrates the model devised for testing.

\section{RESULTS}

\subsection{Data Preprocessing and Assumptions}

Three of the variables measuring drinking quantity were trichotomized to reduce unacceptable skewness and kurtosis associated with lower levels of drinking and abstinence for the group of mothers whose children were not diagnosed with FAS. Current weekend drinking (number of drinks consumed Friday, Saturday, and Sunday) was coded as follows: $0=$ "no drinks", $1=$ " $1-6$ drinks", $2=$ "7 or more drinks". Variables representing quantity of drinking on a typical day before and during pregnancy were coded as follows: $0=$ "no drinks", $1=$ " $1-4$ drinks", $2=$ " 5 or more drinks". These ordinal variables were then treated as if continuous (Tabachnick and Fidell, 2007) in subsequent analyses, as were dichotomous variables.

Varying amounts of data were missing on the measures, from no missing data for IOM final diagnosis to 36\% missing for mother's height. Logarithmic transformations were applied to several of the variables within the SAS PROC MI (multiple imputation, SAS Institute, 2006) software to comply with multivariate normality assumptions of the multiple imputation process. These variables then were back-transformed to create five complete (imputed) data sets, each with $N=563$. Impossible values (e.g., negative number of problem behaviors) 
were adjusted to fall within reasonable range. Relative efficiency was greater than .89 for all variables, indicating relatively little uncertainty regarding missing values. Although deviating from normality, these imputed data sets were considered appropriate for robust estimation in structural equation modeling. Analyses of the five imputed data sets produced negligible differences among them. Therefore only the results from the first imputation are reported. Nineteen cases were identified through Mahalanobis distance as multivariate outliers with $p<.001$. Analyses with and without the outliers were not substantively different, so the 19 cases were retained in reported analyses.

Structural equation modeling through EQS (Bentler and Wu, 1995) indicated that these data deviated significantly from normality, Mardia's Normalized Coefficient $=63.34, p<.001$. Therefore maximum likelihood estimation was used in EQS modeling with Satorra-Bentler chisquare model tests and with adjustment of standard errors to the extent of nonnormality (Ullman, 2007).

\subsection{Predicting Dysmorphology from Maternal Characteristics via Sequential Regression}

Means and percentages for each variable used in the advanced analyses for each variable in the entire sample are in Table 1. These data represent the values for all children and mothers, both cases and controls. Table 2 shows the results of sequential regressions on dysmorphology for three factors indicating maternal characteristics: physical, demographic, and childbearing. Table 3 presents the results of preliminary sequential regressions on dysmorphology for drinking variables. In each regression, the variables hypothesized to be more highly related to dysmorphology and/or easiest to ascertain were given the higher priority.

Maternal physical characteristics significantly predict dysmorphology, $F(3,559)=33.18, p$ $<.001, R^{2}=.15$, with confidence limits from .10 to .20 . Table 2 shows that height and weight most strongly predict dysmorphology. Once these two measures are taken into account, head circumference fails to add significantly to prediction, $F_{\text {inc }}(1,559)=0.73, p=$. 48. Head circumference was examined in the model as a possible indicator that the mother might herself have an FASD or some other form of cognitive impairment. Maternal demography also significantly predicts dysmorphology, $F(3,559)=58.23, p<.001, R^{2}=$. 24 , with confidence limits from .18 to .30 . All of the demographic measures (rural residence, maternal education, and Hollingshead measures of socioeconomic status (SES)) add significantly to predictability of the dysmorphology. In addition, maternal childbearing indices significantly predict dysmorphology, $F(3,559)=11.19, p<.001, R^{2}=.06$, with confidence limits from .02 to .10 . Table 2 shows that gravidity most strongly predicts dysmorphology among the three measures. Once gravidity is taken into account, no further predictability is provided by parity and age at delivery of index child, $F_{\text {inc }}(2,559)=0.26, p$ $=.61$.

Maternal drinking significantly predicts dysmorphology, $F(7,555)=33.47, p<.001, R^{2}=$. 15 with confidence limits from .22 to .35 . Table 3 shows that the three measures of drinking during pregnancy each add significantly to prediction of dysmorphology as they enter the regression equation in the prescribed order. Once those three are taken into account, there is no further statistically significant predictability added by including the four measures of current drinking and drinking before pregnancy, change in $F_{\text {inc }}(4,559)=2.14, p=.07$. Note, however, that current bingeing does add to prediction of dysmorphology beyond that of the other six drinking variables, $B=-2.57, p=.037$ if all items were to enter a regression equation simultaneously. 


\subsection{Structural Equation Model of Children's Physical Characteristics}

The hypothesized model is in Figure 1, with circles representing latent variables (factors) and rectangles representing measured variables. The format for reporting SEM results follows Ullman (2007). Lines with single arrows represent hypothesized direction of prediction (e.g., from maternal physical characteristics to children's physical characteristics). Arcs with double arrows represent hypothesized correlations between factors (i.e., between maternal physical characteristics and demography).

It was hypothesized that an array of children's physical characteristics, including dysmorphology, is predicted by the four maternal factors: physical characteristics, demography, childbearing characteristics, and drinking behavior before and during the index pregnancy as well as at the time of interview. Correlations are hypothesized between maternal physical characteristics and her demography, between maternal physical and childbearing characteristics, and between childbearing and demographic characteristics. It was also hypothesized that drinking behavior would correlate with maternal physical and demographic characteristics.

The test of the hypothesized model indicated significant differences between hypothesized and observed covariance matrices, Satorra-Bentler Chi square $(221, N=563)=2037.94, p$ $<.001$. The robust comparative fit index (CFI) of .80 reflects a poor fit, as well. The model was significantly improved by adding two pairs of correlated residuals suggested by the Lagrange multiplier test. Residuals for the two binge drinking variables, before and during pregnancy, were correlated as were the residuals between narrow vermillion and dysmorphology. This indicates that the strengths of these pairs of relationships are not fully captured by the hypothesized model. Additional improvement to model fit was achieved by omitting the two measures of current drinking as well as some children's physical characteristics (height, weight, OFC and PFL). The difference between hypothesized and modified models was strong, Satorra-Bentler Chi square difference $(112, N=563)=1709.35$, $p<.001$.

This modified model still produced significant differences between the estimated and observed covariance matrices, Satorra-Bentler Chi square $(109, N=563)=328.60, p<.001$, but the fit was improved considerably, robust CFI $=.96$, RMSEA $=.06$. A bivariate correlation was performed between the 27 common unstandardized parameter estimates (of the original 32) from the hypothesized and final models, to support the addition of post hoc modifications $(r(295)>=.88, p<.001)$. This indicates a good fit between the hypothesized and final models.

Figure 2 shows unstandardized and standardized coefficients for the final model. All of the measures loaded significantly on their respective factors. The added correlations between residuals, although significantly enhancing model fit, do not add substantively to interpretation. As predicted, drinking behavior is a relatively strong predictor of these children's physical characteristics $(\beta=0.61, p<.001)$. The greater the drinking behavior, the greater the child's physical anomalies. Children's physical anomalies are also predicted by demographic measures $(\beta=0.23, p<001$.) The more favorable the demographic characteristics (e.g., more education, urban rather than rural location) the more favorable the child's physical characteristics. However, maternal physical characteristics do not predict her child's dysmorphology, narrow vermillion, or diagnosis once other predictors are taken into account $(\beta=.06, p>.05)$. Childbearing experience likewise does not significantly predict child physical anomalies $(\beta=0.04, p>.05)$.

Taking into account the relationships among all of the measures, well over half (62\%) of the variance in children's physical characteristics was accounted for by the combination of 
mother's physical characteristics, demography and drinking behavior, despite the marginal model fit at various points in the analysis.

\section{DISCUSSION}

\subsection{Overall findings: Drinking Factors Are the Most Significant}

In the individual, sequential, regression analyses of the specific maternal physical, demographic, and childbearing variables, significance was found for each domain. That is, each domain is an important factor of size predicting the birth of child with FAS or PFAS. The demographic measures of SES were the strongest predictors (Adjusted $R^{2}=.23$ ) especially rural residence and maternal education. The maternal physical traits of the mother were also significant predictors of FASD outcomes (Adjusted $R^{2}=.15$ ), followed by childbearing variables (Adjusted $R^{2}=.05$ ).

As expected, the regression model of drinking behavior was the strongest predictor of FAS and PFAS (Adjusted $R^{2}=.29$ ) with drinking and binge drinking during pregnancy, and quantity during pregnancy all very strong predictors upon entry to the model. It appears from the Beta weight analysis that daily quantity during pregnancy, daily quantity before pregnancy, and the nominal measurement of drinking during pregnancy are all very robust, single predictors of FASD.

Turning now to the structural equation model, of the four factors utilized as the independent variables, drinking was the most powerful. Specifically, the number of drinks consumed on a drinking day during pregnancy, daily drinks before pregnancy, and current total drinks on the weekend, are all well-quantified measures of binge or heavy, episodic drinking. This clearly shows the statistical power gained from specific quantification of drinking style, particularly heavy episodic drinking on a particular day or days.

The influence of the maternal drinking variable was followed in prediction by maternal demographic, then physical traits, and finally the childbearing variables. The poor predictive ability of the childbearing variables was surprising, as other researchers (Sokol, et al., 1986; Abel, 1998) and our own research team, using other methods, other samples, and other techniques of analysis (Viljoen, et al., 2002; May, et al., 2005; 2008) have found gravidity, parity, and age at delivery to be quite important. But their influence seems to wane when multiple, other variables enter the model with appropriate statistical controls. Similarly, maternal physical characteristics predict variables related to her child's size, but not the child's dysmorphology, narrow vermillion, or IOM final diagnosis. Therefore this SEM application indicates a single summary, comprehensive scenario by which variables other than alcohol consumption are highly associated with FASD dysmorphology. Among South African Coloureds, challenging environmental living conditions (e.g., regular, entrenched patterns of heavy episodic drinking two days each week, poor nutrition in the rural areas, low education, and in some cases, multiple generations of stunting from binge drinking in the pre-natal period) appear to contribute substantially and significantly in this multiple correlation model (May, et al., 2005; 2008). This is probably why the demographic variables are more powerful predictors in the SEM analysis than are the childbearing variables. One might expect that in another population, with less regular and severe episodic drinking practices and fewer socioeconomic challenges, that the childbearing variables would be more robust predictors of child physical characteristics of FASD (see also Bingol et al., 1987; Abel and Hannigan, 1995).

\subsection{The Extant Literature and This Study}

The overall results produced by the structural equation model were insightful, and their significance and value eminates, to a great degree, from highly complete maternal risk data 
from outreach in the entire population. Over the years of this ongoing study, the South Africa maternal interview data have proven to be quite complete, and very accurate in all three waves of research (Viljoen, et al., 2002; May et al., 2005; 2007; 2008). South African Coloured women of this region, because of the normative and cultural setting surrounding drinking behavior (e.g., a lack of stigma regarding alcohol consumption in the prenatal period), have been forthcoming with rich and detailed information regarding their drinking practices. It should be noted here that the $46 \%$ of South African women who report drinking during pregnancy in our studies corresponds well to recent findings from not only South African studies in antenatal clinics (Croxford and Viljoen, 1999), but also to France where $47 \%$ reportedly drank during pregnancy and $13 \%$ drank more than 4 standard European units per week (Malet et al., 2006). Furthermore, the population-based studies in South Africa, using active case ascertainment for both FASD cases and random selection of comparison cases in public schools, provide nearly complete access to maternal, physical, demographic, and childbearing information within an entire population. Consent for participation for the children has always been exceptionally high (83-99\%), and none of the contacted mothers of FASD children have refused interviews over the years. Only 3.8\% have denied drinking when dysmorphology clearly indicates otherwise, but this is an astoundingly low percentage of denial given the nature of these studies on a highly sensitive topic. A recent study in Sweden that combined biomarker data with interviews about alcohol consumption during pregnancy, estimated a denial of drinking in over $60 \%$ of the participants (Wurst et al., 2008). Therefore, given such rich and complete maternal data, it is not surprising that the SEM modeling of maternal variables explains $62 \%$ of the overall variance in child characteristics. We do not know what accounts for the remaining variance. One could speculate that nutritional deficiencies (Keen et al., 2010), cognitive/behavior stimulation of affected children and other remediation factors provided to the children in their first years of life may account for some additional variance. But collecting further data from this population, with improved interviewing approaches and even more rigorous measures, may help reduce the residual, unexplained variance even further in future studies.

The results of this study are similar in many ways to those of the previous multiple correlation study of maternal risk of Sokol et al. (1986). Our results indicate, as did theirs, that independent measures of binge or heavy episodic drinking are the most powerful predictor of FAS. Also SES was important in their model, with child bearing variables (gravidity and maternal age) somewhat less important.

\subsection{Limitations}

There are limitations to this study. First, given the unique socio-cultural, physical, and environmental conditions in this town and its surrounding rural areas of the Western Cape Province of South Africa, it is difficult to know how applicable these findings may be to mainstream populations of the U.S.A. and Europe. Second, how do these various factors relate to all levels of diagnoses of an FASD? The data set employed here, by methodology and design, utilized only the two diagnoses characterized by the most dysmorphia: FAS and PFAS. Therefore, it is not known what the effect would be if less dysmorphic diagnoses, especially ARND, were also sought via alterations in our active ascertainment methodology and more cases of ARND were available for this analysis. But given the current state-of-theart of ARND diagnosis, this may not be an important consideration, especially given that this is a study which begins with dysmorphology, most of which is present in the diagnoses of FAS and PFAS. Finally, while two thirds of the sample employed in these models was obtained through random methods, we do not know what the results would be if a census of all children were assessed or if the study utilized a totally random sample. Such untargeted methods would have been even more logistically difficult than the massive and time consuming data collection process employed here. They would also be very expensive and 
prohibitive to impossible given the large number of cases of FAS and PFAS that were needed for this analysis. The statistical methods and corrections utilized here have employed appropriate techniques of adjustment and modification throughout the analysis to ensure that the selectivity employed by oversampling small children for the cases of FAS and PFAS (and therefore all children likely to have an FASD) was minimized. The final structural equation model provides a good fit between the hypothesized model constructed from extant literature. It should be noted that we know of no other, extenting FASD data set that is equal to, or better for, the utilization of the statistical methods used in this paper. However, we suggest that any interpretation of the specific or exact variable values, weights and factors produced in the model be viewed cautiously, especially in other populations.

\subsection{Conclusion: Applicability to Other Populations}

This study is quite insightful for the particular population studied, South African Coloureds in the Western Cape Province, and the relative contributions of drinking (pattern and quantity) and other co-factors of risk have been defined. The fascinating question that this analysis has raised is: how are these risk factors similar to, or different from, predominantly high and middle SES populations in a more developed country where the nutrition, childbearing, and drinking patterns are substantially different (Eriksson, 2007)? What are the maternal risk predictors or correlates of FASD in the U.S.A. and European general populations when examined in a similar fashion? There is a substantial gap in our knowledge of the complex interaction of multiple maternal risk factors between what we now know in South Africa and in other countries in the U.S. and Europe with more developed populations. Hopefully, the future will provide access to other populations for similar FASD studies with in large, representative samples.

\section{Acknowledgments}

We thank the mothers and children who provided the information for this study. The interviewers for this study have been exceptional: Julie Croxford, Leslie Brooke, Anna Susan Marais, cudore Snell, Magdalena September, Loretta Hendricks, Leana Marais were the interviewers for the three phases of the study, and Dicky Naude served as the driver and logistician for certain parts of the effort. Gwyneth Moya and Chandra Stellavato, University of New Mexico student employees, also deserve thanks for their assistance in data entry. Finally, Phyllis Trujillo Lewis and Cheryl Ritson assisted with important tasks of manuscript preparation and submission.

Role of the Funding Source

This research was funded in part by grants RO1AA09440, RO1/UO1AA11685, and RO1 AA15134 from the National Institute on Alcohol Abuse and Alcoholism (NIAAA) and the NIH National Center on Minority Health and Health Disparities (NCMHD).

\section{REFERENCES}

Abel EL. An update on the incidence of FAS: FAS is not an equal opportunity birth defect. Neurotoxicol. Teratol. 1995; 17:437-443. [PubMed: 7565490]

Abel, EL. Fetal Alcohol Abuse Syndrome. New York: Plenum Press; 1998.

Abel EL, Hannigan JH. Maternal risk factors in Fetal Alcohol Syndrome: provocative and permissive influences. Neurotoxicol. Teratol. 1995; 17:445-462. [PubMed: 7565491]

Abel EL, Sokol RJ. Maternal and fetal characteristics affecting alcohol's teratogenicity. Neurobehav. Toxicol. Teratol. 1986; 8:329-334. [PubMed: 3531901]

Adnams CM, Kodituwakku P, Hay A, Molteno CD, Viljoen D, May PA. Patterns of cognitive-motor development in children with fetal alcohol syndrome from a community in South Africa. Alcohol. Clin. Exp. Res. 2001; 25:557-562. [PubMed: 11329496]

Alvik A, Haldorsen T, Groholt B, Lindeman R. Alcohol consumption before and during pregnancy comparing concurrent and retrospective reports. Alcohol. Clin. Exp. Res. 2006a; 30:510-515. [PubMed: 16499492] 
Alvik A, Haldorsen T, Groholt B, Lindemann R. Alcohol consumption before and during pregnancy comparing concurrent and retrospective reports. Alcohol. Clin. Exp. Res. 2006b; 30:510-515. [PubMed: 16499492]

Alvik A, Heyerdahl S, Haldorsen T, Lindeman R. Alcohol use before and during pregnancy: a population-based study. Acta Pediat. 2006c; 85:1292-1298.

Bad Heart Bull LB, Kvigne VL, Leonardson GL, Lacuia L, Welty TK. Validation of a selfadministered questionnaire for prenatal alcohol use in Northern Plains Indian women. Am. J. Preven. Med. 1999; 16:240-243.

Badger TM, Hidestrand M, Shankar K, McGuinn WD, Ronis MJ. The effects of pregnancy on ethanol clearance. Life Sci. 2005; 77:2111-2126. [PubMed: 15925387]

Baily S. Women with alcohol problems: a psycho-social perspective. Drug Alcohol Rev. 1990; 9:125131. [PubMed: 16840132]

Bentler, PM.; Wu, EJC. Computer Software. Encino, CA: Multivariate Software, Inc; 2005. EQS for Windows.

Bingol N, Schuster C, Fuchs M, Iosub S, Turner G, Stone RK, Gromisch DS. The influence of socioeconomic factors on the occurrence of fetal alcohol syndrome. Adv. Alcohol Subst. Abuse. 1987; 6:105-118. 1987. [PubMed: 3425475]

Crome IB, Glass Y. The DOP system: a manifestation of social exclusion. A personal commentary on "alcohol consumption amongst South African workers.”. Drug Alcohol Depend. 2000; 59:207208. [PubMed: 11203455]

Croxford J, Viljoen D. Alcohol consumption by pregnant women in the Western Cape. S. Afr. Med. J. 1999; 89:962-965. [PubMed: 10554632]

Czarnecki DM, Russell M, Cooper ML, Salter D. Five -year reliability of self reported alcohol consumption. J. Stud. Alcohol. 1990; 51:68-76. [PubMed: 2299853]

Darrow SL, Russell M, Cooper ML, Mudar P, Frone MR. Sociodemographic correlates of alcohol consumption among African-American and white women. Women Health. 1992; 18:35-50. [PubMed: 1462601]

Dean, AG.; Dean, JA.; Coulambier, D.; Brendel, KA.; Smith, DC.; Burton, AH.; Dickers, RC.; Sullivan, K.; Faglen, RF.; Arnir, TG. Epi Info, Version 6: A Word Processing Data Base, and Statistical Program for Epidemiology in Microcomputers. Atlanta, Georgia: Centers for Disease Control and Prevention; 1994.

Eriksson UJ. Fetal ethanol exposure during pregnancy - how big is the problem and how do we fix it? Acta Paediatrica. 2007; 96:1557-1559. [PubMed: 17937681]

Ernhart CB, Sokol RJ, Martier S, Moron P, Nadler D, Ager JW, Wolf A. Alcohol teratogenicity in the human: a detailed assessment of specificity, critical period, and threshold. Am. J. Obstet. Gynecol. 1987; 156:33-39. [PubMed: 3799767]

Floyd RL, Decouflé P, Hungerford DW. Alcohol use prior to pregnancy recognition. Am. J. Prev. Med. 1999; 17:101-107. [PubMed: 10490051]

Flynn HA, Chermack S. Prenatal alcohol use: the role of lifetime problems with alcohol, drugs, depression, and violence. J. Stud. Alcohol Drugs. 2008; 69:500-509. [PubMed: 18612565]

Hannigan JH, Chiodo LM, Sokol RJ, Janisse J, Ager JW, Greenwald MK, Delaney Black V. A 14-year retrospective maternal report of alcohol consumption in pregnancy predicts pregnancy and teen outcomes. Alcohol. 2010; 44:583-594. [PubMed: 20036487]

Hankin JR. Fetal alcohol syndrome prevention research. Alcohol Res. Health. 2002; 26:58-65. [PubMed: 12154653]

Hoyme HE, May PA, Kalberg WO, Kodituwakku P, Gossage JP, Trujillo PM, Robinson LK. A practical clinical approach to diagnosis of fetal alcohol spectrum disorders: clarification of the 1996 Institute of Medicine Criteria. Pediatrics. 2005; 115:39-47. [PubMed: 15629980]

Jacobson JL, Jacobson SW, Sokol RJ. Increased vulnerability to alcohol-related birth defects in the offspring of mothers over 30. Alcohol. Clin. Exp. Res. 1996; 20:359-363. [PubMed: 8730230]

Jacobson JL, Jacobson SW, Sokol RJ, Ager JW. Relation of maternal age and pattern of pregnancy drinking to functionally significant cognitive deficit in infancy. Alcohol. Clin. Exp. Res. 1998; 22:345-351. [PubMed: 9581639] 
Jacobson SW, Jacobson JL, Sokol RJ, Martier SS, Ager JW, Kaplan MG. Maternal recall of alcohol, cocaine, and marijuana use during pregnancy. Neurotoxicol. Teratol. 1991; 13:535-540. [PubMed: 1758408]

Kaskutas LA, Graves K. Pre-pregnancy drinking: how drink size affects risk assessment. Addiction. 2001; 96:1199-1209. [PubMed: 11487425]

Kaskutas LA, Kerr WC. Accuracy of photographs to capture respondent-defined drink size. J. Stud. Alcohol Drugs. 2008; 69:605-610. [PubMed: 18612577]

Keen CL, Uriu-Adams JY, Skalny A, Grabeklis A, Grabeklis S, Green K, Yevtushok L, Wertelecki W, Chambers $\mathrm{CD}$. The plausibility of maternal nutritional status being a contributing factor to the risk for fetal alcohol spectrum disorders: the potential influence of zinc status as an example. BioFactors. 2010; 36:125-135. [PubMed: 20333752]

Khaole NC, Ramchandani VA, Viljoen DL, Li TK. A pilot study of alcohol exposure and pharmacokinetics in women with or without children with fetal alcohol syndrome. Alcohol. 2004; 39:503-508.

King AC. Enhancing the self-report of alcohol consumption in the community: two questionnaire formats. Am. J. Pub. Health. 1994; 84:294-296. [PubMed: 8296958]

Kristjanson AF, Wilsnack SC, Zvartau E, Tsoy M, Nivikov B. Alcohol use in pregnant and nonpregnant Russian women. Alcohol. Clin. Exp. Res. 2007; 31:299-307. [PubMed: 17250623]

Maier SE, West JR. Drinking patterns and alcohol-related birth defects. Alcohol Res. Health. 2001; 25:168-174. [PubMed: 11810954]

Malet L, de Chazeron I, Llorca PM, Lemery D. Alcohol consumption during pregnancy: an urge to increase prevention and screening. Eur. J. Epidemiol. 2006; 21:787-788. [PubMed: 17106762]

May PA, Hymbaugh KJ, Aase JM, Samet JM. Epidemiology of fetal alcohol syndrome among American Indians of the Southwest. Soc. Biol. 1983; 30:374-385. [PubMed: 6336013]

May PA, Gossage JP, Brooke LE, Snell CL, Marais A-S, Hendricks LS, Croxford JA, Viljoen DL. Maternal risk factors for fetal alcohol syndrome in the Western Cape Province of South Africa: a population-based study. Am. J. Public Health. 2005; 95:1190-1199. [PubMed: 15933241]

May PA, Fiorentino D, Gossage JP, Kalberg WO, Hoyme HE, Robinson LK, coriale G, jones KL, del Campo M, Tarani L, Romeo M, kodituwakku PW, Deiana L, Buckley D, Ceccanti M. The epidemiology of FASD in a province in Italy: prevalence and characteristics of children in a random sample of schools. Alcohol. Clin. Exp. Res. 2006; 30:1562-1575. [PubMed: 16930219]

May PA, Gossage JP, Marais AS, Adnams CM, Hoyme HE, Jones KL, Robinson LK, Khaole NCO, Snell C, Kalberg WO, Hendricks L, Brooke L, Stellevato C, Viljoen DL. The epidemiology of fetal alcohol syndrome and partial FAS in a South African community. Drug Alcohol Depend. 2007; 88:259-271. [PubMed: 17127017]

May PA, Gossage JP, Marais A-S, Hendricks L, Snell C, Tabachnick BG, Stellavate C, Buckley DG, Brooke L, Viljoen DL. Maternal risk factors for fetal alcohol syndrome and partial fetal alcohol syndrome in South Africa: a third study. Alcohol. Clin. Exp. Res. 2008; 32:738-753. [PubMed: 18336634]

Molarius A, Seidell JC, Sans S, Tuomilehto J, Kuulasmaa K. Educational level, relative body weight, and changes in their association over 10 years: an international perspective from the WHO MONICA Project. Am. J. Public Health. 2000; 90:1260-1268. [PubMed: 10937007]

Pierce DR, West JR. Blood alcohol concentration: a critical factor for producing fetal alcohol syndrome. Alcohol. 1986; 3:269-272. [PubMed: 3638973]

Pierog S, Chandavsu O, Wexler I. The fetal alcohol syndrome: some maternal characteristics. Int. J. Gyn. Obstet. 1979; 16:412-415.

Primatesta P, DelCorno G, Bonazzi MC, Waters WE. Alcohol and pregnancy: an international comparison. J. Pub. Health Med. 1993; 15:69-76. [PubMed: 8471303]

Robles N, Day NL. Recall of alcohol consumption during pregnancy. J. Stud. Alcohol. 1990; 51:403407. [PubMed: 2232792]

SAS Institute Inc. SAS/STAT software, Version 9. Cary, NC: 2005.

Serdula M, Williamson DF, Kendrick JS, Anda F, Byers T. Tends in alcohol consumption by pregnant women: 1985 through 1988. JAMA. 1991; 265:876-879. [PubMed: 1992184]

Drug Alcohol Depend. Author manuscript; available in PMC 2012 December 1. 
Shankar K, Hidestrand M, Liu X, Xiao R, Skinner CM, Simmen FA, Ronis MJ. Physiologic and genomic analyses of nutrition-ethanol interactions during gestation: implications for fetal ethanol toxicity. Exp. Biol. Med. 2006; 231:1379-1397.

Shankar K, Ronis MJ, Badger TM. Effects of pregnancy and nutritional status on alcohol metabolism. Alcohol Res. Health. 2007; 30:55-59. [PubMed: 17718402]

Sobell LC, Sobell MB, Leo GI, Cancilla A. Reliability of a timeline method: assessing normal drinkers' reports of recent drinking and a comparative evaluation across several populations. $\mathrm{Br}$. J. Addict. 1988; 83:393-402. [PubMed: 3395719]

Sokol RJ, Ager J, Martier S, Debanne S, Ernhart C, Kuzma J, Miller SI. Significant determinants of susceptibility to alcohol teratogenicity. Ann. NY Acad. Sci. 1986; 477:87-102. [PubMed: 3468841]

SPSS Inc. Computer Software. Chicago: SPSS Inc; 2005. SPSS for Windows, Rel. 13.

Stratton, KR.; Howe, CJ.; Battaglia, FC. Institute of Medicine, Division of Biobehavioral Sciences and Mental Disorders, Committee to Study Fetal Alcohol Syndrome and National Institute on Alcohol Abuse and Alcoholism. Washington, D.C.: National Academy Press; 1996. Fetal alcohol syndrome diagnosis, epidemiology, prevention, and treatment.

Tabachnick, BG.; Fidell, LS. Using Multivariate Statistics. 5th. Ed.. Boston: Allyn and Bacon; 2007.

Thomas JD, Garrison M, O’Neill TM. Perinatal. choline. supplementation attenuates behavioral alterations associated with neonatal alcohol exposure in rats. Neurotoxicol. Teratol. 2004; 26:3545. [PubMed: 15001212]

Thomas JD, Wasserman EA, West JR, Goodlet CR. Behavioral deficits induced by bingelike exposure to alcohol in neonatal rats: importance of developmental timing and number of episodes. Dev. Psychobiol. 1996; 29:433-452. [PubMed: 8809494]

Ullman, JB. Structural equation modeling. In: Tabachnick, BG.; Fidell, LS., editors. Using Multivariate Statistics. Boston: Allyn and Bacon; 2007. p. 770-772.

Viljoen D, Croxford J, Gossage JP, Kodituwakku PW, May PA. Characteristics of mothers of children with fetal alcohol syndrome in the Western Cape Province of South Africa: a case control study. J. Stud. Alcohol. 2002; 63:6-17. [PubMed: 11925060]

Waterson EJ, Murray-Lyon IM. Drinking and smoking patterns amongst women attending an antenatal clinic - II during pregnancy. Alcohol. 1989; 24:163-173.

West JR, Goodlett CR. Teratogenic effects of alcohol on brain development. Ann. Med. 1990; 22:319325. [PubMed: 2291839]

Whaley SE, O'Connor MJ. Increasing the report of alcohol use among low-income pregnant women. Am. J. Health Promot. 2003; 17:369-372. [PubMed: 12858616]

Wurst FM, Kelso E, Weinmann W, Pragst F, Yegles M, Sundström Poromaa I. Measurement of direct ethanol metabolites suggests higher rate of alcohol use among pregnant women than found with the AUDIT-a pilot study in a population-based sample of Swedish women. Am. J. Obstet. Gynecol. 2008; 198:1-5. [PubMed: 18166295] 


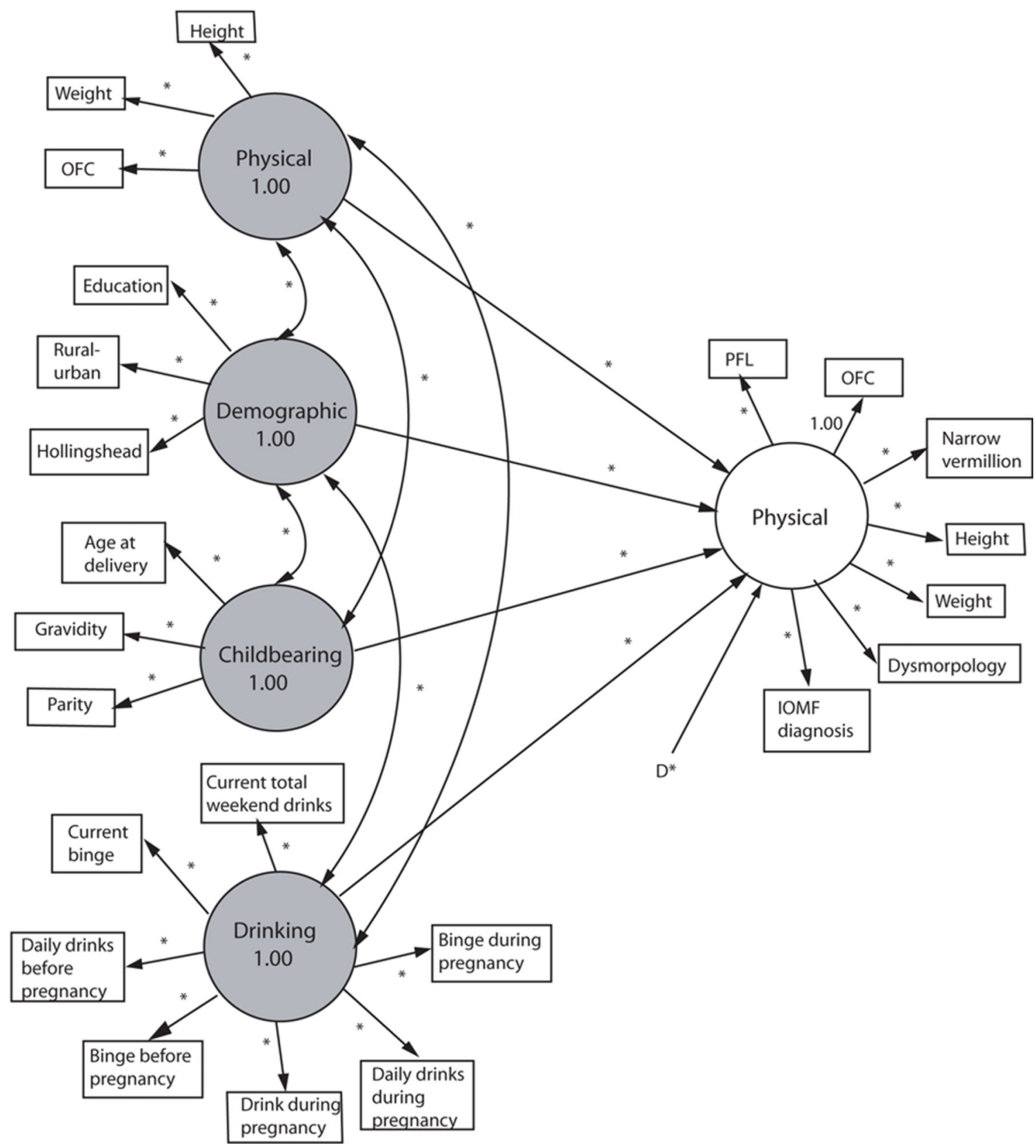

Figure 1.

Hypothesized model of children's characteristics predicted from maternal characteristics. Asterisks are parameters to be estimated. $\mathrm{D}^{*}$ indicates disturbance (error) for the dependent latent variable. All residual variances for measured variables $\left(\mathrm{E}^{*}\right)$ also are to be estimated (not shown). 


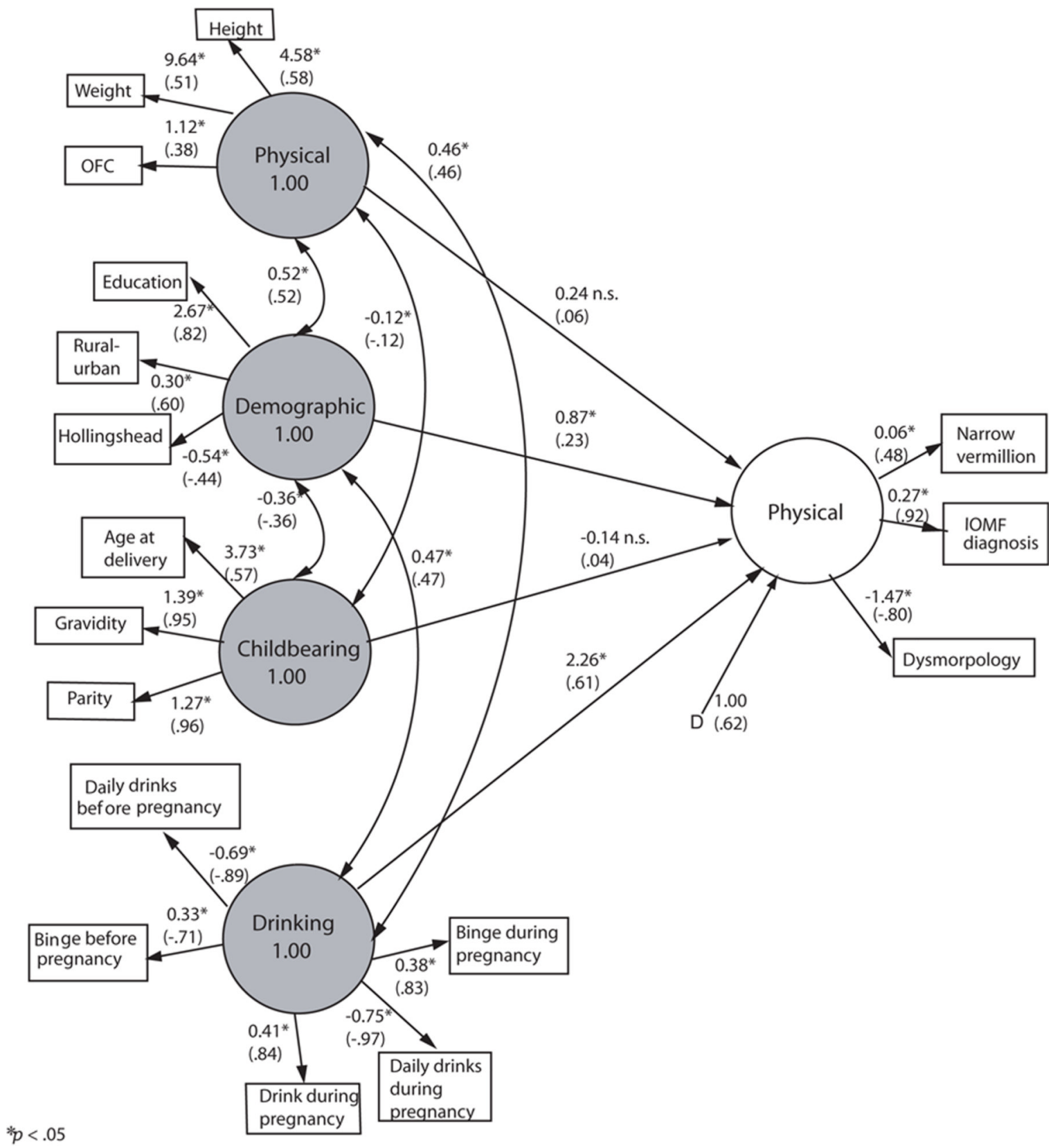

Figure 2.

Final model of children's characteristics predicted from maternal characteristics. Unstandardized and standardized (in parentheses) parameter estimates. Residuals for measured variables are not shown. 
Table 1

Frequencies and Means of Variables Included in Structural Equation Models $(\mathrm{n}=561)$

\begin{tabular}{|c|c|}
\hline Variable & \\
\hline Mother's Educational Level, Mean Years (SD) & $7.0(3.31)$ \\
\hline \multicolumn{2}{|l|}{ Occupations (\%) } \\
\hline (Hollingshead Occupational Codes) & 0.0 \\
\hline \multicolumn{2}{|l|}{$\begin{array}{l}\text { Higher executives, major professionals, } \\
\text { owners of large businesses }\end{array}$} \\
\hline $\begin{array}{l}\text { Business managers, medium businesses, } \\
\text { lesser professionals, school teachers, nurses }\end{array}$ & 1.1 \\
\hline $\begin{array}{l}\text { Administrative personnel, small businesses, } \\
\text { minor professionals, school teachers without degrees }\end{array}$ & 4.7 \\
\hline Clerical and sales, technician, little businesses & 3.2 \\
\hline Skilled manual (including crafts workers and artists) & 1.1 \\
\hline Semiskilled (factory worker, or farm work who operates machinery) & 8.8 \\
\hline Unskilled (farm worker, tender of vines, unspecified and unemployed) & 70.1 \\
\hline Homemaker & 8.4 \\
\hline Student, disabled, or no occupation & 2.6 \\
\hline Gravidity, Mean (SD) & $3.1(1.43)$ \\
\hline Parity, Mean (SD) & $2.9(1.30)$ \\
\hline Current Use of Alcohol, Total Drinks Consumed Friday-Sunday, Mean (SD) & $3.4(7.31)$ \\
\hline Current Use of Alcohol, Binging (3+) in week preceding interview, \% & 22.8 \\
\hline $\begin{array}{l}\text { Use of Alcohol in } 3 \text { months before pregnancy, } \\
\text { quantity of drinks consumed per typical drinking day, Mean (SD) }\end{array}$ & $2.4(3.84)$ \\
\hline Binging (3+) in 3 months before pregnancy, $\%$ & 30.0 \\
\hline Age during pregnancy, Mean (SD) & $26.3(6.29)$ \\
\hline \multicolumn{2}{|l|}{ Residence during pregnancy, \% } \\
\hline Rural & 43.4 \\
\hline Urban & 56.6 \\
\hline Drank during pregnancy, $\%$ & 49.1 \\
\hline $\begin{array}{l}\text { Use of Alcohol during pregnancy, } \\
\text { quantity of drinks consumed per typical drinking day, Mean (SD) }\end{array}$ & $2.2(3.99)$ \\
\hline Binging (3+) during pregnancy, $\%$ & 30.7 \\
\hline Child's height (cm), Mean (SD) & $115.8(7.17)$ \\
\hline Child's weight (kg), Mean (SD) & $20.2(4.18)$ \\
\hline Child's palpebral fissure length (cm), Mean (SD) & $2.4(0.18)$ \\
\hline
\end{tabular}




\begin{tabular}{|l|c|}
\hline Variable & \\
\hline Child's head circumference (OFC)(cm), Mean (SD) & $50.1(1.90)$ \\
\hline Child has narrow vermilion border, $\%$ & 38.2 \\
\hline Child's total dysmorphology score, Mean (SD) & $10.4(6.75)$ \\
\hline Child's verbal IQ, Mean (SD) & $81.0(13.98)$ \\
\hline Child's performance IQ, Mean (SD) & $83.6(10.85)$ \\
\hline
\end{tabular}




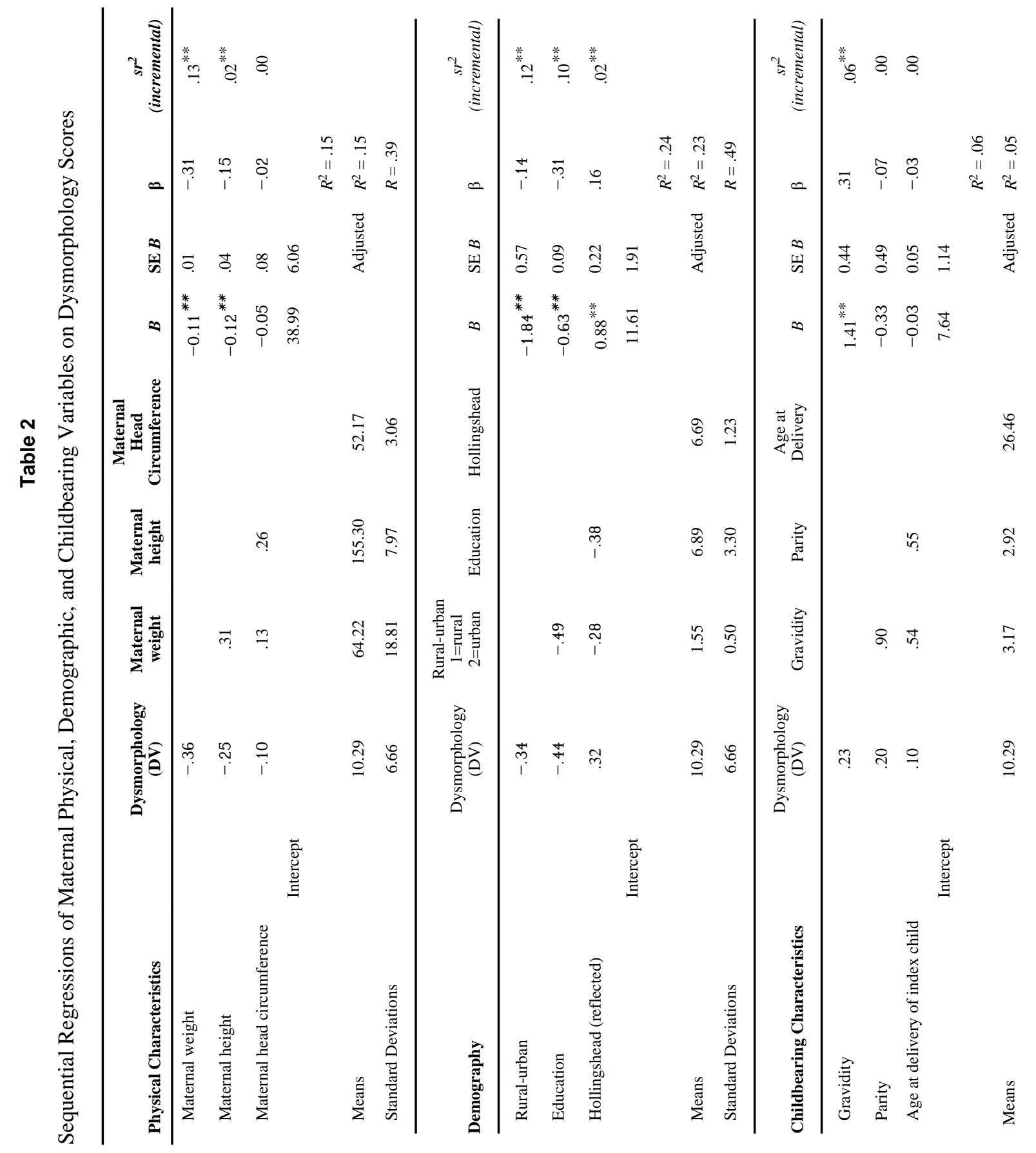




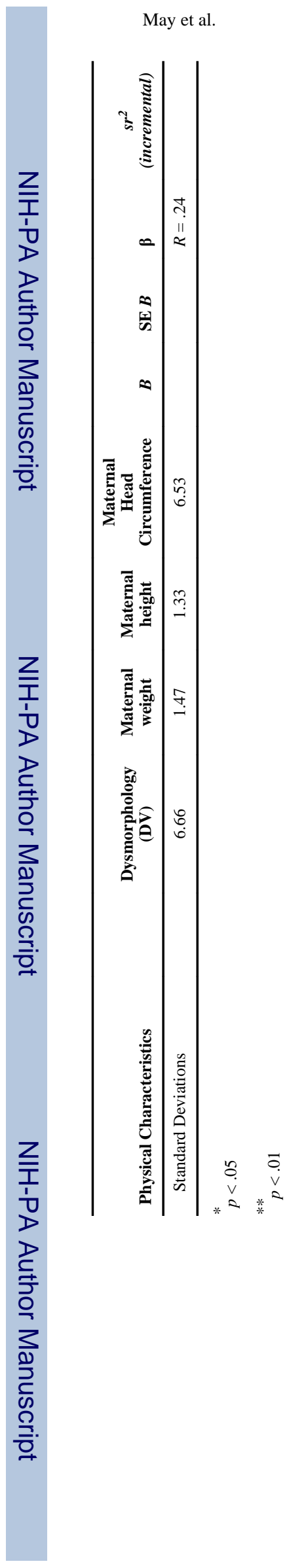

Drug Alcohol Depend. Author manuscript; available in PMC 2012 December 1. 


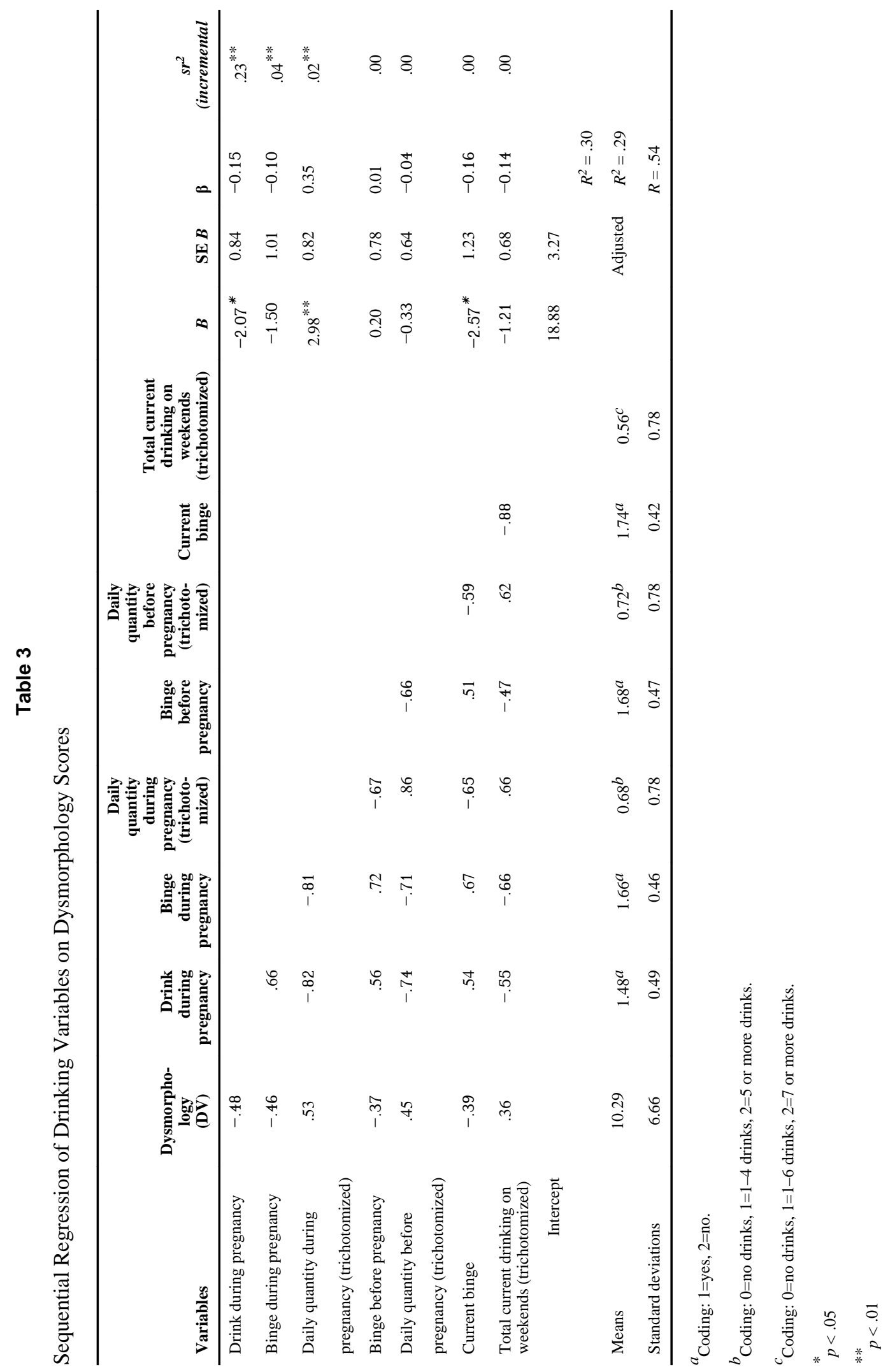

